CONTINGENT CITIZENS 



\title{
CONTINGENT CITIZENS
}

\section{SHIFTING PERCEPTIONS OF LATTER-DAY SAINTS IN AMERICAN POLITICAL CULTURE}

\author{
Edited by SPENCER W. MCBRIDE, \\ Brent M. Rogers, and Keith A. ERekson
}


Copyright (C) 2020 by Cornell University

All rights reserved. Except for brief quotations in a review, this book, or parts thereof, must not be reproduced in any form without permission in writing from the publisher. For information, address Cornell University Press, Sage House, 512 East State Street, Ithaca NY 14850.

First published 2020 by Cornell University Press

Library of Congress Cataloging-in-Publication Data

Names: McBride, Spencer W., editor. | Rogers, Brent M., editor. | Erekson, Keith A., editor. | Jortner, Adam Joseph. Some little necromancy.

Title: Contingent citizens : shifting perceptions of Latterday Saints in American political culture / edited by Spencer W. McBride, Brent M. Rogers, and Keith A. Erekson.

Description: Ithaca : Cornell University Press, 2020. Includes bibliographical references and index.

Identifiers: LCCN 2019037679 (print) | LCCN 2019037680 (ebook) | ISBN 9781501716737 (hardcover) | ISBN 9781501749544 (paperback) | ISBN 9781501716744 (pdf) | ISBN 9781501716751 (ebook)

Subjects: LCSH: Church of Jesus Christ of Latter-day Saints-Political activity-History. | Church of Jesus Christ of Latter-day Saints-Public opinion-History. Mormons-Political activity—History. | MormonsPublic opinion-History. | Political cultureUnited States-History. | Public opinion-United States-History.

Classification: LCC BX8643.P6 C66 2020 (print) |

LCC BX8643.P6 (ebook) | DDC 289.3/73-dc23

LC record available at https://lccn.loc.gov/ 2019037679

LC ebook record available at https: / / lccn.loc.gov/ 2019037680

Cover image: Salt Lake Temple with U.S. flag hung to commemorate Utah's statehood, 1896. Photograph by George W. Reed. Courtesy of Special Collections, J. Willard Marriott Library, The University of Utah. 